\title{
Critical Thinking and Culturally Sustaining Teaching: Developing the Historical Literacy of Māori and Pasifika Undergraduates in Aotearoa/New Zealand
}

\section{Nancy November', Sean Sturm², 'Ema Wolfgramm-Foliaki²}

${ }^{1}$ Department of Music, University of Auckland, New Zealand, ${ }^{2}$ Centre for Learning and Research in Higher Education, University of Auckland, New Zealand.

\begin{abstract}
In this paper, we explore critical thinking in the context of developing culturally sustaining historical literacy in Māori (New Zealand Indigenous) and Pasifika (Pacific Island) students at a large, multicultural university in Aotearoa/New Zealand. Critical thinking and culturally sustaining historical literacy might seem like an odd couple insofar as critical thinking tends to be associated with liberal Western (academic) culture. Such students can resist developing their critical thinking because culturally sustaining 'critical being' is a threshold concept and requires a flexible, yet clearly structured pedagogical approach from teachers. But the development of critical being is vital to culturally sustaining teaching because of the role that the associated skills and dispositions play in supporting cultural autonomy and voice. We conducted research talanoa (Tongan, 'conversations') with nineteen teachers of a range of ethnicities from across the historical disciplines at the University of Auckland to document the pedagogical strategies that they used to develop the critical thinking skills of their Māori and Pasifika students in a culturally sustaining way: fostering peer dialogue that draws on personal experience; practising perspective-taking; drawing on popular culture for its contemporary and cultural relevance; drawing on one's culture in choosing relevant topics; and creating learning spaces conducive to critical being.
\end{abstract}

Keywords: Historical literacy; critical thinking; culturally sustaining pedagogy. 


\section{Introduction}

Critical thinking and culturally sustaining teaching can seem like an odd couple. After all, critique emerged from élite Western universities and might seem to contradict the respect for tradition and authority shown by many non-Western cultural and intellectual traditions (Chakrabarty, 2008). And yet critical thinking is vital for culturally sustaining education precisely because it can foster cultural autonomy and voice. It can enable students to understand and articulate their ways of being and knowing through developing a sense of belonging to a community of learners; using knowledge from the past to shape their futures; and leading the struggle for Western recognition of indigenous ways of being and knowing.

Recent research suggests that teachers in historical disciplines need to rethink how they enable students to become 'critical beings': individuals who, in Ron Barnett's (1997, p. 109) words, 'exert some unity of critical power over their experiences in relation to knowledge, themselves and the world.' But current research into, and definitions of, historical literacy do not adequately acknowledge the cultural backgrounds of indigenous learners across the historical disciplines and levels, let alone sustain them culturally (Paris, 2012; Paris \& Alim, 2014). Nor do they recognise the vital role of historical literacy in empowering indigenous students (Leonard \& McLaren, 2002). These shortcomings exist in mainstream educational institutions at all levels in Aotearoa/New Zealand, despite ground-breaking research on critical literacy, by Māori teachers in particular (see, for example, Cooper, 2008; Edwards, 2010), and a policy environment that advocates cultural competency for teachers of Māori and Pasifika students from early childhood to secondary level (Ministry of Education, 2011; Ministry of Education, 2018). In this paper, we explore how teachers foster culturally sustaining critical historical literacy in Māori and Pasifika students at a multicultural comprehensive university in Aotearoa/New Zealand.

\subsection{Critical Thinking for Critical Being}

We adopt a threefold definition of critical thinking that encompasses (1) attitudes such as openness to (others') ideas and their sharing; (2) actions such as collaboration, synthesis and evaluation of ideas, and reflection; and (3) outcomes such as seeing others' perspectives, shifting one's attitudes, and having new insights. We hold that teachers need to think about how to develop the dispositions that foster such critical attitudes, actions and outcomes (Perkins, Jay, \& Tishman, 1993). But the more capacious criticality implied in Barnett's term 'critical being' also implies that teachers should consider ways to promote critical thinking in and about the discipline and, we would argue, ways to ensure that their concept of critical thinking is 'culturally sustaining' (Paris \& Alim, 2014). The message that teachers send students through 'traditional' pedagogy in the disciplines can inhibit students' development of culturally sustaining critical thinking. For example, teachers can more readily foster students' perspective-taking, and thus their reflexivity about their discipline and culture, if 
they incorporate in their teaching well-structured opportunities for active and/or collaborative learning that recognises cultural practices and preferences for learning, rather than relying on lecturing, which can promote a view of the lecturer as 'oracle.'

\subsection{Culturally Sustaining Teaching}

Of course, to foster their students' critical being, teachers might take up one of the existing international models of critical historical literacy. For example, the History Learning Project at Indiana University advocates teaching students to 'decode' the discipline by learning the steps an expert might take to overcome 'bottlenecks' in their understanding (Middendorf \& Pace, 2004, p. 1213). For history, that involves interpreting sources, maintaining appropriate emotional distance, understanding the limited knowledge of historical actors, identifying appropriately with people of the past, making good arguments and contextualising events (Middendorf, Pace, Shopkow, \& Diaz, 2007). Or they might take up the model of the Historical Thinking Project (2014), which identifies the 'big six' threshold concepts of critical historical literacy: historical significance, the use of primary source evidence, continuity and change, cause and consequence, the acknowledgement of different historical perspectives (or world-views), and the ethical dimension of historical interpretation-and provides teaching strategies for working with these concepts at various levels (Seixas \& Morton, 2012).

However, while such existing international models of critical historical literacy are useful, they offer a one-size-fits-all solution, emerge from a single historical discipline (History), and largely ignore the cultural background of the learners they seek to engage. The exceptions are studies of 'content-area literacy' (historical literacy in particular disciplines; see, for example, Broomhead [2005] in Music). And, although such studies explore what we are teaching when we teach historical literacy, for the most part, they fail to address how we might best teach it. The same is true of most studies of history teaching from Aotearoa/New Zealand, which have tended to focus on pre-tertiary education (see, for example, Sheehan, Hunter \& Howson, 2013). Further, both the international models of historical literacy and local practitioners in the historical disciplines at tertiary level have tended to privilege Pākehā/Pālagi (European) notions of what historical literacy is and how it ought to be taught, not to mention Pākehā/Pālagi interpretations of the shared history of Aotearoa/New Zealand.

\section{Critical Thinking and Culturally Sustaining Teaching: An Odd Couple?}

In our study, our research group of one Pākehā New Zealander, one New Zealander of Pākehā and Māori descent, and one New Zealander of Pasifika descent undertook research conversations, or talanoa (Vaioleti, 2006), at our university with nineteen teachers from a range of ethnicities and historical disciplines (including Anthropology, Architecture, Classics and Ancient History, Education, English, History, Māori Studies and Music) who aimed to 
develop the critical literacy of their students in a culturally sustaining way. We undertook to document how teachers in the historical disciplines in a large comprehensive university in Aotearoa/New Zealand might teach to foster the 'critical being' of Māori and Pasifika tertiary students across the historical disciplines. We adopted talanoa, rather than traditional research interviews, because we were focused less on eliciting knowledge or information from the participants than on cultivating relationships and 'reach[ing] a state of understanding' between us and the participants as fellow teachers with similar aims and challenges in their teaching (Prescott, 2008, p. 132). Thus, we did not rely on a schedule of questions and allowed the conversation to take its own course, led by the common concern of the participants and us in sharing aspects of our teaching that we had found to help and hinder the process of fostering critical being in 'our' undergraduate Māori and Pasifika students. In what follows, we present a descriptive summary of what the teachers shared with us. (We have shared our reflections on the process of the talanoa elsewhere [see Hindley, November, Sturm, \& Wolfgramm-Foliaki, 2020].)

The teachers offered three main reasons why critical thinking in the historical disciplines is challenging for undergraduate students, Māori and Pasifika students in particular. Firstly, students can find perspective-taking foreign. One teacher whose students encounter religious texts summarised the problem of personal or cultural 'interference.' Students can appreciate that other people hold different beliefs:

[Teacher A:] Often when we're looking at [a] religious text, a person's faith will stop them being critical, analytical. I was telling students, if you want to ... bring your own faith perspective, that's fine, but just to be honest about that at the start. [...] I don't think they get that often....

But they can find it challenging to be similarly reflexive about their beliefs: '[Teacher A:] when I try to say... to an extent ... we interpret things, ... in a way that suits us. I'm not sure if they quite get that...'

Students can be anxious about presenting their ideas, let alone about taking a position on someone else's ideas in an essay or presentation:

[Teacher B:] In the past, [... students] had to give oral presentation ... and I graded them on these presentations. But then some people said, 'it makes me anxious and I can't do it.'

This teacher noted that this was especially the case with Māori and Pasifika students, who were more likely than Pākehā/Pālagi students to be the first in their family to attend university.

One teacher, from a non-Pākehā/ Pālagi cultural background, thematised the problem: critical thinking can imply disrespect for one's elders and is associated with Western liberal thinking: 
[Teacher C:] I went to university, and I would always sit in the back, and I would always be quiet, and I would never say anything in my whole undergrad because for me, it was: I respect my elders, and my professor is my elder. [... T] hat's a liberal kind of idea to be open[, meaning,] you can talk back to me, if you will; back it up with evidence. [...] I think that was ... very difficult for me ... because of my cultural background [and is for] a lot of Pacific Islanders.

\section{Critical Thinking and Culturally Sustaining Teaching: Bridging the Gap}

To address these challenges in developing students' critical thinking, with Māori and Pasifika students in particular, the teachers we talked with offered six pedagogical strategies.

\subsection{Use peer-to-peer dialogue that draws on personal experience}

Teacher $\mathrm{C}$ noted that indigenous students were more inclined to 'open up' with him than with older or European professors. So one strategy might be to employ tutors of similar age and cultural background to the students; or, better, to engage students in peer-to-peer dialogue that can draw on their personal cultural experience as a gateway to critical thinking. To do so, teachers will have to address students' reluctance to use personal experience as evidence.

[Teacher C:] They open up to me like a sibling, but ... sometimes I see them a bit more open with their peers than with me. But ... it doesn't have to be me if ... they are willing to have a critical conversation about the topic ... with each other.

A strategy that Teacher $\mathrm{C}$ uses is to set 'ground rules' for the critical conversation that include using one's personal cultural experience as evidence:

[Teacher C:] I kind of remind them, don't forget about, 'in your opinion.' And I will try and be an example of that and say 'look I have experienced this, I've read this, and this is how I'm drawing this conclusion' $[-\ldots]$ you know the experience as evidence.... I hail from Utah; highly conservative[,] ... heavily religious kind of a community. So ... I ... over-emphasise my disclaimer....

\subsection{Assist students with perspective-taking so they can move beyond their perspective}

While students might find it challenging to present their ideas, some find perspective-taking with others' ideas even more difficult. Teachers can offer advice about how to do so:

[Teacher A:] Within religious studies and theology, we do have students who have a strong faith commitment and some of them just avoid the difficult questions about those that hurt them just to make their point. [T]here's a Tongan student, he's writing about some debate ... and his initial idea ... was, 
like, I'm going to show why the [other 'side'] are so wrong. And I said, don't start from that premise because that makes your argument sound ... biased. Start with, I'm going to look at both sides of the argument, and sure, you can see which argument seems a bit stronger, but show them both.

One teacher hosts a weekly office hour in 'interactive reading,' when they and the students engage actively with a written text without formal assessment. The session has proved especially popular with Māori and Pasifika students.

\subsection{Make the topics contemporary and culturally relevant}

Understanding and making critical arguments about a text or topic can be easier if one already has an opinion on the topic or a related one. To this end, in one Australasian history course, the teacher allows students to select contemporary and culturally relevant topics:

[Teacher D:] The students seem to really get that there can be different types of interpretation within history through looking at something like the Australian context. They really get how this historian who might be writing about a fairly traditional conserving history of the education of children in New South Wales from 1850s to 1950s. They get how he is doing what he does, which is just going into the archives, find evidence relating to arts and policies and all of that sort of things. They get how that's very different from an oral history project which just ask people involved what their experiences were like. And I can see how each have something to offer, and we need that to balance our view of the past with that.

\subsection{Use popular culture to achieve contemporaneity and cultural relevance}

Drawing on popular culture is a short cut to finding contemporary and culturally relevant topics. But teachers must ensure that students retain critical distance on an 'owned' or their own culture. Teacher E gave an example of a student writing effectively about their favourite boy band, but countered it with an example of another student limited by cultural ownership:

$[\mathrm{O}]$ ne of my research areas is gender-based violence in religion.... I find a few students have said they are Pasifika themselves and ... they say [that] before colonisation there was complete gender equality in the Pacific Islands. How do I engage in this conversation with someone who is from that culture? I don't want to ... say they're completely wrong. But [my response] was quite hard to frame: something like colonising myself.... 


\subsection{Help students draw on their culture in choosing relevant topics}

Teacher D gave students the (popular) option to write about oral history and its contribution to history education, which occasioned some critical thinking about historiography: 'some argue that it's actually the point that instead of traditional history using written sources, oral history can work together...' A Pasifika student agreed, as the teacher attested: 'in that moment of the essay was quite clear that she was thinking, "I can relate to this. This is what I know being Tongan. And thinking about my family and how the story is told.",

\subsection{Create learning environments conducive to holistic 'critical being'}

Several teachers acknowledged the challenge of encouraging critical thinking in spaces that are designed for 'oracular' teaching. They created a physical space and groups that were conducive to interaction and communication:

[Teacher F:] I think the university should have more spaces where students can eat and congregate because in the past I did 'directive reading' in lunchtime and it was very successful....

[Teacher G:]: [S]mall groups have been the most successful ... for [students] becoming vulnerable and having them think about their historical achievements that relates to the topic ... or try to make a connection to it they want to share. The more I get [students] to share, the more the people feel more comfortable to share....

\section{Conclusion}

To open historical narratives to critical reflection can empower students to make history their own. But to do so in a culturally sustaining way requires that teachers not take for granted that students know how to critique and feel comfortable doing it, or that there is one way to practise critique. The pedagogical strategies offered by the teachers from the historical disciplines at our university with whom we talked represent a modest endeavour to foster culturally sustaining critical historical literacy in Māori and Pasifika students. It remains ro be seen how they also support the students, as Django Paris (2012, p. 95) argues that culturally sustaining pedagogy does, 'in sustaining the cultural and linguistic competence of their communities while simultaneously offering access to dominant cultural competence.'

\section{Acknowledgments}

We are grateful to the New Zealand Council for Educational Research for Teaching and Learning Research Initiatives funding, which enabled research for this article. 


\section{References}

Barnett, R. (1997). Higher education: A critical business. Buckingham: SRHE/Open University Press.

Broomhead, P. (2005). (Re)Imagining literacies for music classrooms. In R. J. Draper (Ed.), (Re)imagining content-area literacy instruction (pp. 69-81). New York, NY: Teacher's College Press.

Chakrabarty, D. (2008). Provincializing Europe: Postcolonial thought and historical difference. Princeton, NJ: Princeton University Press.

Cooper, G. (2008). Tawhaki and Māui: Critical literacy in indigenous epistemologies. Critical Literacy: Theories and Practices, 2(1), 37-42.

Edwards, S. (2010). Matauranga Māori literacies: Indigenous literacy as epistemological freedom v. Eurocentric imperialism. In V. Arbon (Ed.), Indigenous voices, indigenous research (pp. 26-37). Grovedale: World Indigenous Nations Higher Education Consortium.

Hindley, P., November, N., Sturm, S., \& Wolfgramm-Foliaki, E. (2020). Rolling out the mat: A talanoa on talanoa as a higher education research methodology. In J. Huisman \& M. Tight (Eds.), Theory and method in higher education research. Bingley: Emerald.

Leonard, P., \& McLaren, P. (2002). Decentering pedagogy: Critical literacy, resistance and the politics of memory. In Paulo Freire: A critical encounter (pp. 61-103). New York, NY: Routledge. doi: 10.4324/9780203420263

Middendorf, J., \& Pace, D. (2004). Decoding the disciplines: A model for helping students learn disciplinary ways of thinking. New Directions for Teaching and Learning, 2004(98), 1-12. doi: 10.1002/tl.142

Middendorf, J., Pace, D., Shopkow, L., \& Diaz, A. (2007). Making thinking explicit: Decoding history teaching. The National Teaching and Learning Forum, 16(2), 1-4. doi: 10.1002/ntlf.10092

Ministry of Education. (2018). Tapasā: Cultural competencies framework for teachers of Pacific learners. Wellington: Ministry of Education.

Ministry of Education. (2011). Tātaiako: Cultural competencies for teachers of Māori learners. Wellington: Ministry of Education.

Paris, D. (2012a). Culturally sustaining pedagogy: A needed change in stance, terminology, and practice. Educational Researcher, 41(3), 93-97. doi: 10.3102/0013189X12441244

Paris, D., \& Alim, H. S. (2014). What are we seeking to sustain through culturally sustaining pedagogy? A loving critique forward. Harvard Educational Review, 84(1), 85-100. doi: 10.17763/haer.84.1.9821873k2ht16m77

Perkins, D., Jay, E, \& Tishman, S. (1993). Beyond abilities: A dispositional theory of thinking. The Merrill-Palmer Quarterly, 39(1), 1-21.

Prescott, S. M. (2008). Using talanoa in Pacific business research in New Zealand: Experiences with Tongan entrepreneurs. AlterNative: An International Journal of Indigenous Peoples, 4(1), 127-148. doi: 10.1177/117718010800400111

Seixas, P., \& Morton, T. (2012). The big six historical thinking concepts. Toronto: Nelson. 
Sheehan, M., Hunter, K., \& Howson, J. (2013). 'Thinking historically': The role of NCEA research projects in motivating history students to develop disciplinary expertise. Retrieved from http://www.tlri.org.nz/tlri-research/research-completed/schoolsector/'thinking-historically'-role-ncea-research-projects

Vaioleti, T. M. (2006). Talanoa research methodology: A developing position on Pacific research. Waikato Journal of Education, 12, 21-34. doi: 10.15663/wje.v12i1.296 